\title{
Research
}

\section{Analysis of Gifted and Talented Students' Creative Problem Solving Styles*}

\section{Özel Yetenekli Öğrencilerin Yaratıcı Problem Çözme Stillerinin Analizi}

\author{
Hasan Akdeniz ${ }^{1}$ \& Gülgün Bangir Alpan²
}

\begin{abstract}
This study aimed at analyzing creative problem-solving (CPS) styles of gifted and talented students. The study was conducted as a quantitative study. The study group of the research consisted of 151 students 77 girls ( $51 \%)$; 74 boys $(49 \%)$ who were enrolled in science and art centers in Ankara in the 2019-2020 academic year. Sixty-five (43\%) of students were talented in academics, $44(29 \%)$ talented in music, and $42(28 \%)$ talented in the arts. Data for this study were collected using the "Creative Problem Solving Styles Inventory". Data were analyzed using $\chi 2$ (chi-square) test, Cramer's V coefficient and descriptive statistics. Findings of the study showed that gifted and talented students in the process of the CPS preferred conceptualizer style, generator style, optimizer style, and implementer style respectively. No relation was found between students' CPS styles and their gender. Students' CPS styles differed according to their talent areas (general-music-art).
\end{abstract}

Key Words: creative problem solving, gifted and talented student, creative problem solving styles

\section{Öz}

Bu çalışmanın amacı, özel yetenekli öğrencilerin yaratıcı problem çözme (YPÇ) stillerini analiz etmektir. Araştırma nicel çalışma modelinde tarama desenine göre yürütülmüştür. Araştırmanın çalışma grubunu 2019-2020 eğitim öğretim yılında Ankara ilinde bulunan Bilim ve Sanat Merkezleri'ne kayıtlı 77 (\%51) kız ve 74 (\%49) erkek olmak üzere özel yetenekli 151 öğrenci oluşturmaktadır. Öğrencilerin 65'i (\%43) genel zihinsel yetenek alanına, 44'ü (\%29) müzik yetenek alanına ve 42'si (\%28) görsel sanatlar yetenek alanına kayıtlıdır. Araştırma verileri "Yaratıcı Problem Çözme Stilleri Envanteri" ile toplanmıştır. Veriler $\chi 2$ (ki-kare) testi, Cramer's V katsayısı ve betimsel istatistikler kullanılarak analiz edilmiştir. Verilerin analizi sonucunda, öğrencilerin YPÇ sürecinde sırayla; kavramsallaştırıcı, üretici, geliştirici ve uygulayıcı stili tercih ettikleri belirlenmiştir. Öğrencilerin YPÇ stilleri ile cinsiyetleri arasında bir ilişki tespit edilmemiştir. Öğrencilerin YPÇ stilleri yetenek alanlarına (genelmüzik-görsel sanatlar) göre farklılık göstermektedir Anahtar Sözcükler: yaratıcı problem çözme, özel yetenekli öğrenci, yaratıcı problem çözme stiller

\section{Summary}

Purpose and Significance: Creativity can play an important role in the issue of people's struggles for problems. Therefore, creativity is an essential life skill to prepare individuals to survive with an uncertain future and creativity should be considered a fundamental goal of current education systems (Puccio, 2017). Creativity has commonly been conceptualized as a problem-solving activity (Amabile, 1983; Isaksen, \& Treffinger, 2004; Osborn, 1953). According to Basadur, Graen and Wakabayashi (1990) Individuals' creative problem-solving style can be identified four-styles (generator, conceptualizer, optimizer, implementer). The establishment of a heterogeneous structure in terms of style in organizations, working groups or teams contributes to the higher quality and innovative work. It is thought that it is important to provide for gifted and talented students who

\footnotetext{
" This paper was presented at the VI. Ulusal Üstün Yeteneklilerin Ĕ̆itimi Kongresi, İstanbul, Turkey in October 2019.

${ }^{1}$ Correspondence Author, PhD Student, Gazi University, Educational Technology Department, Ankara, Turkey; hasanakdeniz.gazi@gmail.com, ORCID: 0000-0001-8628-7273

2 Assoc.Prof., Gazi University, Educational Technology Department, Ankara, Turkey. ORCID: 0000-0003-4652-7652

(c) Talent; ISSN 2717-7122 http://talentjournal.net
} 
come to the fore in terms of creativity and problem-solving skills and to provide training to develop these styles. This study is aimed to analyze the creative problem-solving styles of gifted and talented students.

Method: The study was conducted in the form of a quantitative study model. The study group of the research consisted of 151 gifted and talented students registered in science and art centers in Ankara. CPS inventory, which was developed by Basadur et al. (1990). Adaptation of the inventory to the Turkish language was carried out by Akdeniz and Bangir Alpan (2019). The CPS measures two bipolar, orthogonal, dimensions of cognitive activity underlying the creative problem-solving process. The first dimension, apprehension, involves acquiring knowledge or understanding in two different ways. (Experiencing vs. Thinking). The second dimension, utilization, involves applying knowledge or understanding in two different ways: (Ideation vs. Evaluation). The CPS inventory consists of 18 sets of four words. Participants are instructed to rank the words within each set from 1 to 4 , where 1 represents the word "least characteristic of me as a problem-solver" and 4 represents the word "most characteristic of me as a problem-solver." The four words in each set represent, respectively, Experiencing $(X)$, Thinking $(T)$, Ideation (I), and Evaluation (E). Six fourword distractor sets are embedded within the inventory to prevent respondents from identifying patterns and responding stereotypically. The measures of Apprehension and Utilization are constructed from the item rankings. One measure (XT) is constructed by subtracting the T-item score in a word set from the X-item score in the same set, and the other (IE) by subtracting the E-item score from the I-item score. The 12 XT scores constitute a bipolar scale of Apprehension, which represents the preference for Experiencing over Thinking; the 12 IE scores constitute a bipolar scale of Utilization representing the preference for Ideation over Evaluation. Data were analyzed using $\chi 2$ (chi-square) test, Cramer's V coefficient and descriptive statistics.

Results and conclusion: According to Basadur and Goldsby (2016), any CPS style has no advantage over another. All styles are equally important. As a result of the analysis of the data, gifted and talented students in the process of CPS can be said that they respectively prefer conceptualizer style, generator style, optimizer style, and implementer style. No relation was found between students' CPS styles and their gender. Students' CPS styles have differed according to their talent areas (general-music-art).

\section{Giriş}

Yaratıcılık ve inovasyon hızla değişen dünyada bireylerin sahip olması gereken en önemli yaşam becerileri arasında yer almaktadır (Tennant, McMullen \& Kaczynski, 2009; Trilling \& Fadel, 2009). 21.yüzyılın gelişen ihtiyaçları doğrultusunda Bloom'a ait eğitimin bilişsel hedefleri de revize edilerek yaratıcılık, bireylerin elde edebileceği en yüksek bilişsel hedef olarak belirlenmiştir (GurakOzdemir, Acar, Puccio \& Wright, 2019). Bilgi toplumunun gereği olarak bilgiye ulaşmanın kolay olduğu günümüzde bireyleri farklı kılan, sahip oldukları bilgi miktarı değil bilgiyi yeniden yapılandırmaları ve üretmelerini sağlayan yaratıcılık becerileridir (Treffinger, 2001). Bireyler yaratıcılık becerileri sayesinde çevrelerindeki potansiyellerin, fırsatların, yeniliklerin ve sınırsız sayıdaki olasılıkların farkında olur (Snyder, Mitchell, Bossomaier \& Pallier, 2004). Bütün büyük buluşlar (saat, 
cep telefonları, bilgisayarlar, teoriler, sanat eserleri vb.) bireylerin karşılaştıkları problem veya fırsatlar karşısında yaratıcılıklarını kullanmaları sayesinde gerçekleştirilmiştir (Seelig, 2012).

Bir kavram olarak yaratıcılık, Guilford (1950) ve Torrance'nin (1962) öncü çalışmalarının sonucu ortaya çıkmıştır (Sternberg, 2006). Torrance'ye (1962) göre yaratıcılık; problemlere duyarlı olma, problem çözümünde problemi oluşturan öğeleri fark etme, çözüme ilişkin tahminler yürütme, fikir veya hipotezler üretme, hipotezleri test etme ve sonucun ortaya konulmasıdır. Yaratıcılık çok sayıda problemi farklı boyutlardan incelemek ve düşünülmeyen fikirleri ortaya koymaktır (Brown, 1989). Yaratıcılık, mevcut bilinenlerdeki boşlukları ve problemleri bulmak ya da kalıpları değiştirmeye çalışmaktır (Tardif \& Sternberg, 1988). Wallach ve Kogan'a (1965) göre yaratıcllık, hem ıraksak düşünme hem de yakınsak düşünmeyi içeren bir süreçtir. Chien ve Hui'e (2010) göre ise bireylerin problemler karşısında gösterdiği akıcı, esnek ve orijinal davranışlardır. Basadur, Graen ve Wakabayashi (1990) yaratıcılı̆̆ı karşılaşılan problemlere çözüm üretmek için farklı basamaklardan oluşan bir süreç olarak modellemektedir.

Yaratıcılık, bireylerin çalışma alanlarının tamamında yer aldığı için birçok tanımı yapılmıştır (Sak, 2016). Ancak üzerinde uzlaşılan bir tanımı olmadığı gibi yaratıcılıkla ilgili çalışmalarda da farklı yaklaşımların olduğu görülmektedir. Bu yaklaşımlar beş başlık altında incelenebilir (Basadur, Gelade, Basadur \& Perez, 2016; Puccio, 2017). (a) Yaratıcı sürecin ürününü değerlendiren çalışmalar (O'Quin \& Besemer, 1989), (b) yaratıcı kişiliği ya da bireyi tanımlama çalışmaları (Torrance, 1974), (c) yaratıcılığın öğretimini ve gelişimini amaçlayan çalışmalar (Beghetto, 2010; Meadow, Parnes \& Reese, 1959), (ç) yaratıcı performansı etkileyen faktörleri belirleme çalışmaları (Amabile \& Gryskiewicz, 1989) ve (d) yaratıcılığı problem çözme süreci olarak modelleyen çalışmalardır (Basadur, Graen \& Green, 1982; Isaksen \& Treffinger, 1985, 2004; Osborn, 1953; Simon, 1960).

Yaratıcı düşünmenin problem çözme sürecinde kullanımı yaratıcı problem çözme (YPÇ) olarak kavramsallaştırılmış ve "yaratıcılık" ile "yaratıcı problem çözme" kavramları birçok araştırmada birbirinin yerine kullanılmıştır (Ward, Fink, \& Smith, 1999; Mumford, Baughman, Threlfall, Supinski, \& Constanza, 1996; Basadur \& Hausdorf, 1996; Brophy, 1998; Isaksen, Dorval, \& Treffinger, 1994; Runco, Dow \& Smith, 2006).

YPÇ yapılandırılmamış problemlerin çözümü için yeni, orijinal ve uygun çözümler üretmektir (Basadur et al., 1990; Isaksen, Dorval, \& Treffinger, 2011; Osborn, 1953). YPÇ yapılandırılmış aşamalardan oluşan ve problemlere yaratıcı çözümler üretmek kadar bireylerin problem çözme becerilerini de geliştirmeyi hedefleyen bir tekniktir (Isaksen et al., 2011; Sak, 2016).

YPÇ genel bir problem çözme türüdür. Günlük yaşamda karşılaşılan pek çok problem, tek boyutlu değil çok boyutludur ve yaratıcı düşünmeyi gerektirmektedir (Senemoğlu, 2012). YPÇ'de amaç; yaratıcı düşünme, eleştirel düşünme ve analitik düşünme gibi üst düzey düşünme becerilerinin geliştirilmesi, geliştirilen bu becerilerin ilgili süreçler ve disiplinlerde kullanılmasıdır (Özkök, 2004).

YPÇ genellikle çoklu aşamalardan oluşan bir süreç olarak değerlendirilmektedir (Basadur et al., 1990; Couger, 1995; Isaksen et al., 2011; Osborn, 1953; Simon, 1960; VanGundy, 1988). YPÇ'yi açklayan birçok modelin temelini Osborn'un (1953) çalışmaları oluşturmaktadır. Osborn (1953) YPÇ 
sürecini; problemi düzenleme, veri toplama, verilerin analizi, hipotez oluşturma, aydınlanma öncesi kuluçka, parçaları bir araya getirme (sentez), elde edilen fikirleri değerlendirme ve doğrulama olarak açıklamıştır. Parnes (1967) Osborn-Parnes YPÇ modelini; bilgi bulma, problem tanımlama, fikir bulma, çözüm bulma ve kabul oluşturma olarak güncellemiştir (Parnes, Noller, \& Biondi, 1977). Simon (1960) problem çözme sürecini; veri toplama, tasarım, seçim ve uygulama olmak üzere dört aşamada açıklamaktadır. Isaksen ve Treffinger (2004) YPÇ sürecini üç ana ve altı ara basamak olarak aşamalandırmıştır. Lineer bir yapıda olmayan bu basamaklar; problemi anlama (verileri araştırma, problemi sınırlandırma, olanakları yapılandırma), fikir üretme (potansiyel çözüm üretme), eylem için hazırlık (çözüm geliştirme, kabul oluşturma) şeklindedir.

Basadur vd. (1990) YPÇ sürecini Şekil 1'de gösterildiği gibi her biri farklı bilişsel aktiviteyi içeren 8 aşamalı bir süreç olarak açıklamaktadır.

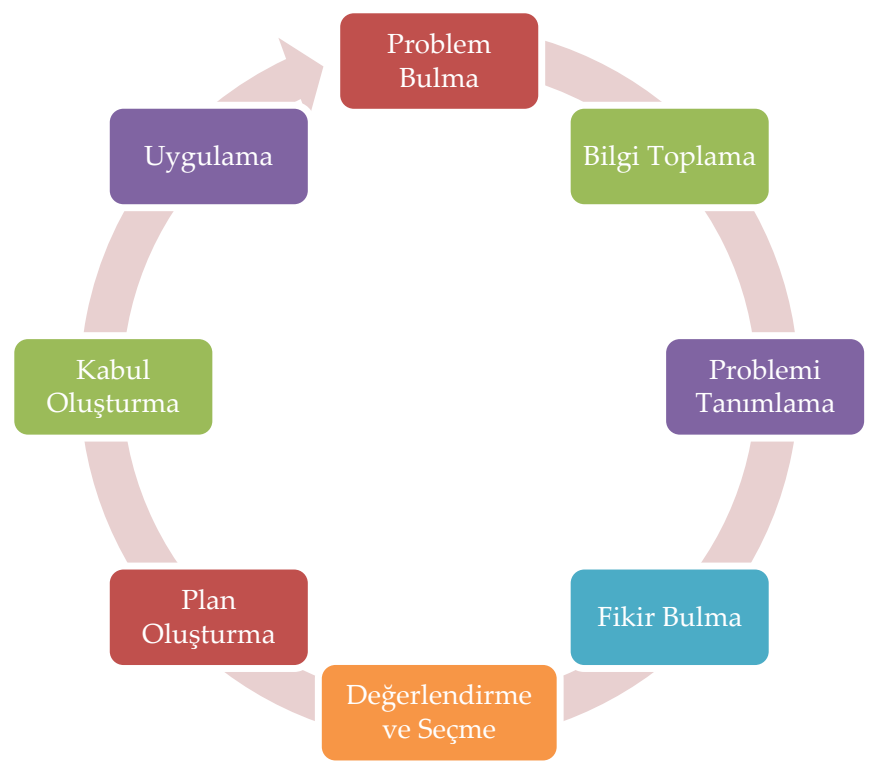

Şekil 1. Yaratıcı Problem Çözme Süreci (Basadur et al., 1990)

Şekil 1 incelendiğinde YPÇ'nin problem bulma, bilgi toplama, problemi tanımlama, fikir bulma, değerlendirme ve seçme, plan oluşturma, kabul oluşturma ve uygulama olmak üzere sekiz aşamadan oluştuğu görülmektedir. Basadur vd. (1990) bir probleme sunulan çözümün yeni bir problemi ortaya çıkarabileceği için YPÇ sürecini döngü olarak ifade etmiştir. YPÇ sürecinin aşamaları ve her bir aşamada gerçekleştirilen etkinlikler (Basadur et al., 1990; Sak, 2016) Tablo 1'de gösterilmiştir.

Tablo 1 incelendiğinde YPÇ'nin her bir aşamasında öncelikle rraksak (çoğul) düşünme sonrasında ise yakınsak (tekil) düşünme becerilerinin kullanıldığı görülmektedir. Ayrıca YPÇ sürecinin problem üretme (problem bulma, bilgi toplama, problemi tanımlama), çözüm üretme (fikir bulma, değerlendirme ve seçme) ve çözümü uygulama (plan oluşturma, kabul oluşturma, uygulama) olarak üç grupta incelendiği söylenebilir. 
Tablo 1. YPÇ Aşamaları ve Süreç Etkinlikleri

\begin{tabular}{|c|c|}
\hline Aşama & Süreç Etkinlikleri \\
\hline Problem Bulma & $\begin{array}{l}\text { - } \quad \text { Durum hakkında bilinenler analiz edilir. } \\
\text { - } \quad \text { Çok fazla sayıda problem alanı belirlenir. } \\
\text { - } \text { Amaçlar belirlenir. } \\
\text { - Belirlenen amaçlar, belli başlı kriterlere göre değerlendirilir. } \\
\text { - } \quad \text { Problem alanı tam olarak anlaşılır. }\end{array}$ \\
\hline Bilgi Toplama & $\begin{array}{l}\text { - Seçilen amaç ile ilgili farklı türden veriler toplanır. } \\
\text { - } \quad \text { Amaç ile en fazla ilgili veriler seçilir. } \\
\text { - } \quad \text { Veriler ilgiliden ilgisize doğru sıralanır. } \\
\text { - Toplanan veriler sistematik bir şekilde analiz edilir. }\end{array}$ \\
\hline Problemi Tanımlama & $\begin{array}{l}\text { - Problem alanı ile ilgili çok fazla sayıda problem belirlenir. } \\
\text { - } \quad \text { Olası problemler farklı açılardan incelenir. } \\
\text { - } \quad \text { Birincil derecede önemli problemler üzerine odaklanılır. } \\
\text { - önemli problem belli başlı kriterlere göre seçilir. }\end{array}$ \\
\hline Fikir Bulma & $\begin{array}{l}\text { - } \quad \text { Belirlenen problemi çözmek için fazla sayıda olası çözüm fikirleri üretilir. } \\
\text { - Urretilen fikirleri tamamlamak için detaylandırmalar yapılır. } \\
\text { - } \quad \text { Yeni fikirler diğerleri ile iliş̧kilendirilir. } \\
\text { - } \quad \text { Eleştiri veya yargılama yapılmaz. } \\
\end{array}$ \\
\hline Değerlendirme ve Seçme & $\begin{array}{ll}\text { - Üretilen çözüm fikirleri sistematik olarak analiz edilir. } \\
\text { - } \quad \text { Çözüm fikirlerini değerlendirmek için fazla sayıda kriter üretilir. } \\
\text { - } \quad \text { Değerlendirme kriterlerini kullanarak çözüm fikirleri değerlendirilir. } \\
\text { - Objektif değerlendirme uygulayarak en iyi çözüm seçilir. }\end{array}$ \\
\hline Plan Oluşturma & $\begin{array}{l}\text { - Eylem planı ayrıntılı olarak hazırlanır. } \\
\text { - Her bir adımda yapılacaklar açıkça belirtilir. } \\
\text { - Çözümün olası olup olmadığını test etmek için pilot uygulama yapılır. }\end{array}$ \\
\hline Kabul Oluşturma & $\begin{array}{l}\text { - Çözümün sunulacağı paydaşların beklentileri dikkate alınarak planlama yapı- } \\
\text { lir. } \\
\text { - Çözümün uygulanmasında karşılaşılabilecek olumlu ve olumsuz durumlar } \\
\text { tahmin edilir. } \\
\text { - Problemi çözmek için gerekenler tam olarak ifade edilir. } \\
\text { - Çözümün uygulanması ile ilgili problemler en aza indirilir. }\end{array}$ \\
\hline Uygulama & $\begin{array}{l}\text { - Çözüm eylem planına göre uygulanır. } \\
\text { - Uygulama süreci denetlenir ve değerlendirilir. } \\
\text { - } \quad \text { Çözümün etkililiği değerlendirilir. } \\
\text { - Yapılan işe ve işlemler detaylı bir şekilde sunulur. }\end{array}$ \\
\hline
\end{tabular}

Bireyler belirli problem çözme aşamalarını ve görevlerini gerçekleştirmek için zamanla güçlü eğilimler geliştirmektedir (Titus \& Koppitsch, 2018). Basadur ve arkadaşlarına (1990) göre her birey problem çözümünde kendine özgü bir stile sahiptir ve YPÇ stilleri bireylerin problem çözerken tercih ettiği bilişsel aktivitelerdir. Bu stiller Şekil 2' de gösterilmiştir.

Şekil 2 incelendiğinde bireylerin problem çözme sürecinde tercih ettikleri üretici, kavramsallaşt1rıcı, geliştirici ve uygulayıcı olmak üzere dört farklı stilin olduğu görülmektedir. Bu stillerin de bilginin kavranması (tecrübe-düşünme) ve uygulanmasının (fikir-değerlendirme) farklı kombinasyonları sonucu ortaya çıktı̆̆ı anlaşılmaktadır.

Üretici stile sahip birey somut deneyimlerle öğrenir. Bilgiyi; fikir, problem ve hipotez üretmek için kullanır. Çalışmayı, problem çözme sürecini veya projeleri başlatmaya meyillidir. Duyularını problemlerin, fırsatların algılanması, yeni bilgilerin elde edilmesi ve veri toplamak için kullanır. 
Bu stilin içerdiği bilişsel aktiviteler (Şekil 1 ve Tablo 1), problem bulma ve bilgi toplamadır (Basadur et al., 1990).

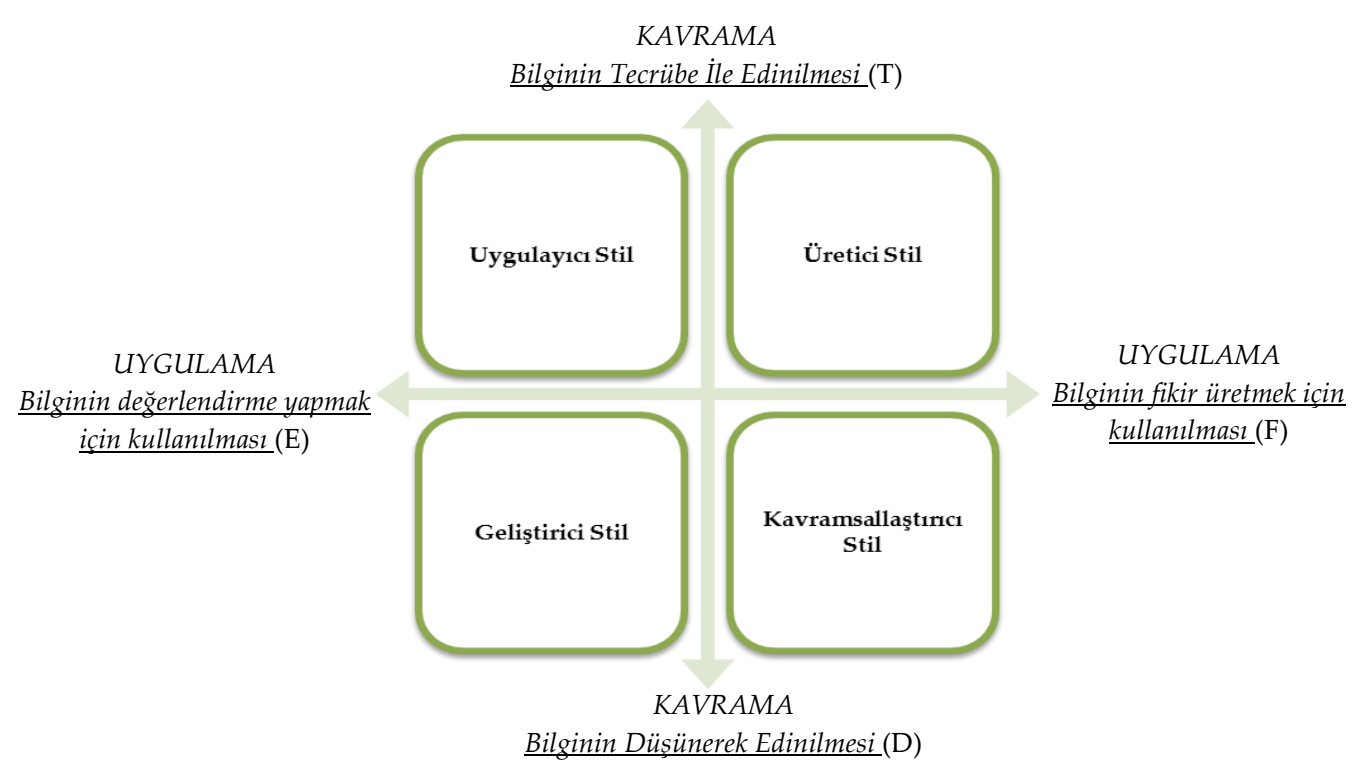

Şekil 2. Yaratıcı Problem Çözme Stilleri (Basadur et al., 1990).

Kavramsallaştırıcı stile sahip birey soyut düşünme ile öğrenir. Bilgiyi fikir, düşünce ve çözüm üretmek için kullanır. Fikirleri bir araya getirmeyi tercih eder. Bu stile sahip birey, problemi açık ve anlaşılır bir biçimde tanımlar. Problem alanını kapsamlı bir şekilde analiz eder. Problemleri tanımlamada, teorik modelleri geliştirmede ve alternatifler oluşturmada başarılıdır. Bu stilin içerdiği bilişsel aktiviteler (Şekil 1 ve Tablo 1), problemi tanımlama ve fikir üretmedir (Basadur et al., 1990).

Geliştirici stile sahip birey soyut düşünme ile öğrenir. Bilgiyi, üretilen çözümleri değerlendirmek ve olası çözümler arasından seçim yapmak için kullanır. Soyut fikirleri pratik çözüm ve planlara dönüştürür. İdeal çözümü/sonucu elde etmek için birçok alternatif çözümden en iyilerini seçer. Bu stilin içerdiği bilişsel aktiviteler (Şekil 1 ve Tablo 1); değerlendirme, seçme ve plan oluşturmadır (Basadur et al., 1990).

Uygulayıcı stile sahip birey somut deneyimlerle öğrenir ve öğrendiklerini değerlendirme yapmak için kullanır. Çalışmayı, problem çözme sürecini veya projeleri bitirmeye meyillidir. Çözümün uygulanması, çıktılarının değerlendirilmesi için problem çözme sürecini değerlendirir. Bu stilin içerdiği bilişsel aktiviteler (Şekil 1 ve Tablo 1), kabul oluşturma ve uygulamadır (Basadur, Gelade \& Basadur, 2014).

YPÇ öğrencilerin gerçek yaşamda karşılaştırdıkları problemleri çözebilmelerine yardımcı olması bakımından da önemlidir. Öğrenciler problem çözme sürecinde düşünme becerilerini daha iyi öğrenirken bu becerileri de karşılaştıkları problemler üzerinde uygulayabilme olanağı bulmaktadır (Runco \& Nemiro 1994). Öğrencilere çözmeleri için problemler sunmak onların yaratıcılık becerilerini geliştirmeye yardımcı olmaktadır. Problemlerin çözümüne çeşitli yollardan ulaşarak akranlarından farklılaşan öğrenciler olarak tanımlanan (MEB, 2019) özel yetenekli öğrenciler için yaratıcılık becerisi, problem çözme sürecinde önemli bir içsel motivasyon kaynağı olabilmektedir (Carr \& Barkowski, 1987). 
Özel yetenekli öğrenci, yaşıtlarına göre daha hızlı öğrenen; yaratıcılık, sanat, liderliğe ilişkin kapasitede önde olan; özel akademik yeteneğe sahip, soyut fikirleri anlayabilen, ilgi alanlarında bağımsız hareket etmeyi seven ve yüksek düzeyde performans gösteren bireydir. Özel yetenekli öğrenciler Bilim ve Sanat Merkezleri'nde (BİLSEM) tanılandığı yetenek alanına (genel zihinsel-görsel sanatlar-müzik) göre eğitim görmektedir (MEB, 2019). BILLSEM'de genel zihinsel yetenek alanı öğrencileri fen bilimleri, sosyal bilimler, matematik ve bilişim branşlarında; müzik ve görsel sanatlar yetenek alanı öğrencileri de kendi alanlarına ait konularda eğitim almaktadır. Bu eğitim sayesinde öğrencilerin yetenek alanlarına ait alt disiplinlerde derinlemesine çalışmalar gerçekleştirerek projeler üretmesi beklenmektedir.

Yaratıcılık ve problem çözme becerisi özel yetenekli öğrencilerin en önemli özelliklerindendir (Çitil ve Ataman, 2018). YPÇ özel yetenekli öğrencilerin eğitiminin genel amacı olan yaratıcılık ve düşünme becerilerinin öğretimi ile yakından ilişkilidir (Treffinger \& Isaksen, 2005). YPÇ özel yetenekli öğrencilerin çeşitli problemlerin çözümünde kullanabileceği bir araçtır (Treffinger \& Parnes, 1979). YPÇ öğrencilere gerçek problemler üzerinde yaratıcı düşünmeyi uygulama fırsatı vermektedir. YPÇ, öğrencilerin yeteneklerini keşfetmelerine ve genişletmelerine yardımcı olmaktadır (Treffinger \& Isaksen, 2005).

Küresel sorunlar ile yakından ilgili ve bu problemlere yönelik fikir üretebilme becerileri yüksek olan özel yetenekli öğrenciler için yapay problemler ya da projeler üzerinde çalışmak ilgi çekici olmayabilir. Bu noktada öğretim etkinlikleri, yapay problemler yerine gerçek yaşam problemleri üzerinde yapılandırıldığında öğrencilerin YPÇ becerilerinin gelişimine daha fazla katkı sağlayabilir (Conklin \& Frei, 2007; Sak, 2009; Treffinger, 2003). Özel yetenekli öğrenciler YPÇ’yi kullandıkça karmaşık görevler ve problemler üzerinde başarılı bir şekilde çalışabileceklerine dair güven ve becerilere sahip olur. Özel yetenekli öğrencilerin doğasında var olan yetenekleri onlar için bireysel güç olarak görülse de takım çalışmasının ve iş birliğinin önemi çağın gereğidir (Tennant et al., 2009; Trilling \& Fadel, 2009). YPÇ öğrencilere, grup çalışmalarında etkili iş birliği içerisinde hareket etmeleri için tanımlanmış aşamalar sağlamaktadır (Treffinger, 2003).

Özel yetenekli öğrencilerin eğitiminde önemli bir yer tutan "Üç Tipli Zenginleştirme” eğitim modelinde, öğrencilere I. II. ve III. tür zenginleştirme etkinlikleri sunulmaktadır (Renzulli 1977; akt. Saranll, 2017). I. ve II. tür zenginleştirme etkinlikleri ile öğrencilerin düşünme, araştırma ve iletişim becerilerinin gelişimi amaçlanırken III. tür zenginleştirme etkinlikleri ile öğrencilerin bireysel ilgilerine göre seçtikleri alanlarda bilgilerini ve yaratıcı düşünmelerini uygulayabilmeleri, disipline özgü içerik ve süreçleri öğrenebilmeleri ve otonom öğrenme becerilerini geliştirmeleri amaçlanmaktadır (Sak, 2012). III. tür zenginleştirme etkinliklerinde YPÇ'nin kullanılmasının öğrencilerin amaçlanan becerileri kazanabilmesi açısından önemli olduğu düşünülmektedir.

Türkiye'de YPÇ ile ilgili çalışmalar incelendiğinde (Çetinkaya, 2013; Demirci, 2014; İslim, 2009; Karabey, 2010; Olgun, 2012; Önol, 2013; Özkök, 2004; Yıldırım, 2014; Yılmaz, 2019) YPÇ stilleri ile ilgili bir çalışmaya rastlanılmamıştır. Yurt dışı literatürde üniversite öğrencilerinin ve farklı meslek gruplarından bireylerin YPÇ stillerinin incelendiği çalışmalar (Basadur et al., 1990; Basadur et al., 
2014; Peterson, 2006; Titus \& Koppitsch, 2018; Wellman, 2014) bulunmaktadır. Özel yetenekli öğrenciler ile gerçekleştirilen çalışmaların ise (Gurak-Ozdemir et al., 2019; Treffinger, \& Isaksen, 2005) oldukça sinırlı olduğu görülmüştür.

Bu araştırmanın genel amacı, özel yetenekli öğrencilerin YPÇ stillerini cinsiyet ve yetenek alanları değişkenleri açısından incelemektir. Bu amaca yönelik olarak aşağıdaki sorulara cevap aranmıştır:

(1) Özel yetenekli öğrencilerin YPÇ stillerinin dağılımı nasıldır?

(2) Özel yetenekli öğrencilerin YPÇ stilleri cinsiyetlerine göre anlamlı bir farklılık göstermekte midir?

(3) Özel yetenekli öğrencilerin YPÇ stilleri yetenek alanlarına göre anlamlı bir farklılık göstermekte midir?

\section{Yöntem}

\section{Araştırmanın Modeli}

Bu çalışmada nicel araştırma modellerinden ilişkisel tarama deseninden yararlanılmıştır. Bu desen kullanılarak özel yetenekli öğrencilerin YPÇ stilleri ile cinsiyet ve yetenek alanı değişkenleri arasındaki ilişki belirlenmeye çalışılmıştır (Creswell, 2012; Erkuş, 2016; Fowler, 2009; Gürbüz ve Şahin, 2017; Karasar, 2019).

\section{Çalışma Grubu}

Araştırmanın çalışma grubunun kolay ulaşılabilir olması gerekmektedir (Büyüköztürk, Çakmak, Akgün, Karadeniz ve Demirel, 2014). Bu yönde amaçlı örnekleme türlerinden ölçüt örnekleme çeşidi kullanılmıştır. Amaçlı örnekleme, araştırmanın problemlerine cevap bulacağına inanılan katılımcıların seçilmesidir (Gürbüz ve Şahin, 2017). Bu çalışmada özel yetenekli öğrencilerin YPÇ stilleri ile cinsiyet ve yetenek alanı değişkenleri arasındaki ilişkiyi belirlemek amaçlandığından dikkate alınan ölçüt, öğrencilerin Bilim ve Sanat Merkezleri'ne kayıtlı olması ile çalışmaya gönüllü olarak katılımlarıdır. Araştırmanın çalışma grubunu 2019-2020 eğitim öğretim yılında Ankara ilinde bulunan Bilim ve Sanat Merkezlerine kayıtlı 77 (\%51) kız ve 74 (\%49) erkek olmak üzere özel yetenekli 151 öğrenci oluşturmaktadır. Öğrencilerin 65'i (\%43) genel zihinsel yetenek alanına, 44'ü (\%29) müzik yetenek alanına ve 42'si (\%28) görsel sanatlar yetenek alanına kayıtlıdır.

\section{Veri Toplama Aracı ve Verilerin Analizi}

Araştırma verileri "Yaratıcı Problem Çözme Stilleri Envanteri” ile toplanmıştır. YPÇ Stilleri Envanteri Basadur vd. (1990) tarafından geliştirilmiştir. Envanterin Türkçe'ye uyarlaması Akdeniz ve Bangir Alpan (2019) tarafından gerçekleştirilmiştir. İki boyuttan oluşan YPÇ Stilleri Envanteri'nin kavrama boyutu için Cronbach alfa iç tutarlılık katsayısı $\alpha=.74$; uygulama boyutu $\alpha=.70$ ve envanterin geneli için $\alpha=.77$ olarak rapor edilmiştir. Bu çalışmada hesaplanan Cronbach alpha iç tutarlık katsayıları ise kavrama boyutu için $\alpha=.81$; uygulama boyutu $\alpha=.84$ ve envanterin geneli için $\alpha=.79$ olarak tespit edilmiştir.

Envanterde her biri 18 eylemden oluşan toplam 4 sütun bulunmaktadır. Envanterdeki her satırdaki 
4 eylem sırasıyla; 1. bilginin tecrübe ile kavranmasını (T), 2. bilginin fikir üretmek için kullanılmasını (F), 3. bilginin düşünerek kavranmasını (D) ve 4. bilginin değerlendirme yapmak için kullanılmasını (E) temsil etmektedir. Ancak envanterde katılımcılara yönlendirme olmaması için sütunlar $1, \ldots . .4$ şeklinde isimlendirilmiştir. Ayrıca her bir sütunda 6 eylem çeldirici/dikkat dağıtıcı olarak kullanıldığından puanlamaya katılmamaktadır. Katılımcılar problem çözücü olarak kendilerini en iyi ifade eden eylem için " 4 ", problem çözücü olarak kendilerini en az ifade eden eylem için " 1 " puan vererek değerlendirme yapmaktadır. Envantere ait örnek puanlama Şekil 3'te gösterilmiştir.

\section{Değerli Katılımcı,}

$\mathrm{Bu}$ envanter, yaratıı problem çözme stilinizi tanımlamak için hazırlanmıștır. Yaratıcı problem çözme envanterinde, her biri 18 eylemden oluşan 4 sütun bulunmaktadır. Satırların birbirleri ile ilişkisi bulunmamaktadır. Problem çözme stilinizi en iyi yansıtan kelimeleri seçmeniz beklenmektedir. Doğru veya yanlıș seçim yoktur. Her bir satırda, sizin problem çözme stilinizi en iyi yansitan eyleme 4 , sonraki en iyi yansitan eyleme 3, sonraki yansitan eyleme 2 ve en az yansitan eyleme 1 puan veriniz ve puanınızı eyleme soluna yazınız. Satırdaki dört eylemin her birine farklı bir puan verdiğinizden emin olun. Örnek bir puanlama aşağıda verilmiştir.

\begin{tabular}{|l|c|c|c|c|c|c|c|}
\hline Puan & SÜTUN 1 & Puan & SÜTUN 2 & Puan & SÜTUN 3 & Puan & SÜTUN 4 \\
\hline 4 & $\begin{array}{c}\text { Denemeler } \\
\text { yaparım }\end{array}$ & $l$ & $\begin{array}{c}\text { Alternatif } \\
\text { üretirim }\end{array}$ & 3 & Plan yaparım & 2 & $\begin{array}{c}\text { Olası } \\
\text { çözümleri } \\
\text { değerlendiririm }\end{array}$ \\
\hline
\end{tabular}

Şekil 3. YPÇ Stilleri Envanterine ait örnek puanlama

Katılımclların verdikleri puanlar sonucunda her bir sütun için $12 \geq$ ile $\leq 48$ puan arasında bir puan elde edilir. Ancak katılımcıların YPÇ stilini belirlemek için birleştirilmiş puanlara ihtiyaç vardır. Birleştirilmiş puanlar, [Sütun 1 (T) - Sütun 3 (D)] ile [Sütun 2 (F) - Sütun 4 (E)] toplam puan farkı alınarak hesaplanır. Bu işlemlerin sonucunda puanlar teorik olarak -36 ile +36 arasında değişmektedir. Elde edilen puanlar Şekil 4'te gösterilen koordinat sistemine kaydedilir. Üretici YPÇ stiline ait örnek bir puanlama Şekil 4'te gösterilmiştir.

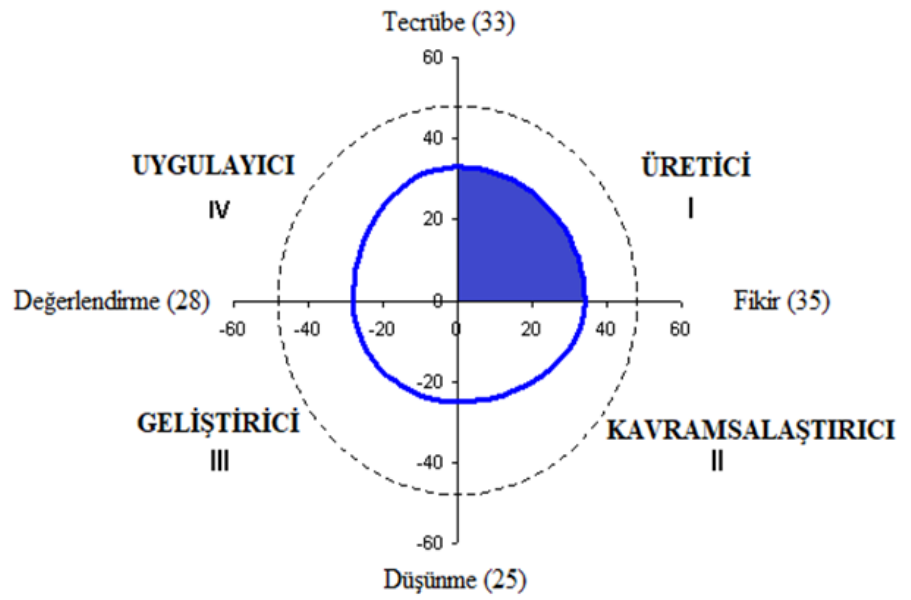

Şekil 4. Üretici YPÇ Stiline Ait Örnek Puanlama

Elde edilen puanlara göre katılımcıların YPÇ Stilleri şu şekilde belirlenmektedir;

- TD puanı pozitif FE puanı pozitif ise "Üretici Stil"

- TD puanı pozitif FE puanı negatif ise "Uygulayıcı Stil"

- TD puanı negatif FE puanı negatif ise "Geliştirici Stil"

- TD puanı negatif FE puanı pozitif ise "Kavramsallaştırıcı Stil". 
Bu çalışmadaki değişkenler (YPÇ stilleri, cinsiyet ve yetenek alanları) kategorik değişken olduğu için verilerin analizinde SPSS 22 istatistik paket programı aracılığıyla $\chi 2$ (ki-kare) testi, değişkenler arasındaki ilişkinin düzeyini hesaplamak için Cramer's V katsayısı ve betimsel istatistikler kullanılmıştır (Gürbüz ve Şahin, 2017). Elde edilen Cramer's V değeri; $0.1 \leq \mathrm{r} \leq 0.3$ (zayıf), $0.3 \leq \mathrm{r} \leq 0.5$ (orta) ve $0.5 \leq \mathrm{r} \leq 1$ (güçlü) yönergeleri dikkate alınarak yorumlanmıştır (Cohen, 1988).

\section{Bulgu ve Yorumlar}

$\mathrm{Bu}$ bölümde araştırmanın alt amaçları yönünde elde edilen bulgulara yer verilmektedir. Özel yetenekli öğrencilerin YPÇ stillerinin dağılımının anlamlı olup olmadığı tek değişkenli kikare testi ile incelenmiştir. Öğrencilerin YPÇ stillerinin dağılımı ve ki-kare analizi sonuçları Tablo 2'de gösterilmiştir.

Tablo 2. Özel Yetenekli Öğrencilerin YPÇ Stillerinin Dağılımı ve Ki-Kare Analizi Sonuçları

\begin{tabular}{lccccc}
\hline YPÇ Stilleri & $\boldsymbol{n}$ & $\mathbf{\%}$ & $\boldsymbol{\chi} \mathbf{2}$ & $\boldsymbol{d f}$ & $\boldsymbol{p}$ \\
\hline Üretici & 37 & 24 & & & \\
Kavramsallaştırıcı & 48 & 32 & & \\
Geliştirici & 34 & 23 & 87.5 & & \\
Uygulayıcı & 32 & 21 & & \\
Toplam & 151 & 100 & & \\
\hline
\end{tabular}

Tablo 2 incelendiğinde özel yetenekli öğrencilerin YPÇ stillerinin dağılımında istatiksel olarak anlamlı bir farklılığın olduğu görülmektedir [ $\chi 2(4)=87.5$, p<.05]. Öğrencilerin \%32'sinin (n=48) kavramsallaştırıcı stile, \%24'ünün (n=37) üretici stile, \%23'ünün (n=34) geliştirici stile, \%21'inin (n=32) uygulayıcı stile sahip oldukları görülmektedir. Bu doğrultuda özel yetenekli öğrencilerinin en fazla kavramsallaştırıcı stili (\%32), en az uygulayıcı stili (\%21) tercih ettikleri söylenebilir.

Özel yetenekli öğrencilerin cinsiyete göre YPÇ stilleri arasında istatiksel olarak anlamlı bir ilişkinin olup olmadığı iki değişkenli ki-kare testi ile incelenmiştir. Öğrencilerin YPÇ stillerinin cinsiyet değişkenine göre dağılımı ve ki-kare analizi sonuçları Tablo 3'te gösterilmiştir.

Tablo 3. Özel Yetenekli Öğrencilerin YPÇ Stillerinin Cinsiyet Değişkenine Göre Dağılımı ve KiKare Analizi Sonuçları

\begin{tabular}{|c|c|c|c|c|c|c|c|}
\hline \multirow[b]{2}{*}{ YPÇ Stilleri } & \multicolumn{2}{|c|}{ K1z } & \multicolumn{2}{|c|}{ Erkek } & \multirow[t]{2}{*}{$x^{2}$} & \multirow[t]{2}{*}{$d f$} & \multirow[t]{2}{*}{$p$} \\
\hline & $n$ & $\%$ & $n$ & $\%$ & & & \\
\hline Üretici & 18 & 23 & 19 & 26 & \multirow{5}{*}{8.5} & \multirow{5}{*}{4} & \multirow{5}{*}{.08} \\
\hline Kavramsallaştırıcı & 25 & 32 & 23 & 31 & & & \\
\hline Geliştirici & 15 & 19 & 19 & 26 & & & \\
\hline Uygulayıcı & 19 & 25 & 13 & 18 & & & \\
\hline Toplam & 77 & 100 & 74 & 100 & & & \\
\hline
\end{tabular}

Tablo 3 incelendiğinde özel yetenekli öğrencilerin cinsiyet değişkenine göre YPÇ stilleri arasında istatiksel olarak anlamlı bir ilişkinin olmadığı anlaşılmaktadır [ $\chi 2(4)=8.5$, p>.05]. Kızların \%23'ü (n $=18)$ erkeklerin ise \%26's1 ( $n=19)$ üretici, kızların \%32'si ( $=25)$ erkeklerin ise \%31'i ( $n=23)$ kavramsallaştırıcı, kızların \%19'u (n=15) erkeklerin ise \%26'sı (n=19) geliştirici ve kızların \%25'i (n=19) erkeklerin ise \%18'i (n=13) uygulayıcı YPÇ stiline sahip oldukları görülmektedir. Bununla birlikte YPÇ sürecinde kız öğrencilerin en fazla kavramsallaştırıcı stili (\%32) en az geliştirici stili (\%19), 
erkek öğrencilerin ise en fazla kavramsallaştırıcı stili (\%31) en az uygulayıcı stili (\%18) tercih ettikleri söylenebilir.

Özel yetenekli öğrencilerin YPÇ stilleri ile yetenek alanları arasında anlamlı bir ilişkinin olup olmadığı iki değişkenli ki-kare testi ile incelenmiştir. Öğrencilerin YPÇ stillerinin yetenek alanlarına göre dağılımı ve ki-kare analizi sonuçları Tablo 4'te gösterilmiştir.

Tablo 4. Özel Yetenekli Öğrencilerin YPÇ Stillerinin Yetenek Alanlarına Göre Dağılımı ve Ki-Kare Analizi Sonuçları

\begin{tabular}{|c|c|c|c|c|c|c|c|c|c|c|}
\hline \multirow[b]{2}{*}{ YPÇ Stilleri } & \multicolumn{2}{|c|}{ Genel Zihinsel } & \multicolumn{2}{|c|}{ Müzik } & \multicolumn{2}{|c|}{ Görsel Sanatlar } & \multirow[t]{2}{*}{$x^{2}$} & \multirow[t]{2}{*}{$d f$} & \multirow[t]{2}{*}{$p$} & \multirow[t]{2}{*}{ Cramer's V } \\
\hline & $n$ & $\%$ & $n$ & $\%$ & $n$ & $\%$ & & & & \\
\hline Üretici & 15 & 23 & 12 & 27 & 10 & 24 & \multirow{5}{*}{76.3} & \multirow{5}{*}{4} & \multirow{5}{*}{.00} & \multirow{5}{*}{.297} \\
\hline Kavramsallaştırıcı & 14 & 22 & 15 & 34 & 19 & 45 & & & & \\
\hline Geliştirici & 18 & 28 & 9 & 20 & 7 & 17 & & & & \\
\hline Uygulayıcı & 18 & 28 & 8 & 18 & 6 & 14 & & & & \\
\hline Toplam & 65 & 100 & 44 & 100 & 42 & 100 & & & & \\
\hline
\end{tabular}

Tablo 4 incelendiğinde özel yetenekli öğrencilerin yetenek alanlarına göre YPÇ stilleri arasında zayıf düzeyde (Cramer's V=.297) ve istatiksel olarak anlamlı bir ilişkinin olduğu anlaşılmaktadır $[\chi 2(4)=76.3, p<.05]$. Başka bir ifade ile özel yetenekli öğrencilerin YPÇ stilleri yetenek alanlarına göre anlamlı şekilde farklılık göstermektedir. Öğrencilerin yetenek alanlarına göre YPÇ stillerinin dağılımları incelendiğinde "genel zihinsel yetenek alanı" öğrencilerinin \%23'ünün ( $n=15)$ üretici, \%22' sinin ( $n=14)$ kavramsallaştırıcı, \%28'inin ( $n=18)$ geliştirici ve \%28'sinin ( $\mathrm{n}=18)$ uygulayıc1; "müzik yetenek alanı" öğrencilerinin \%27'sinin ( $\mathrm{n}=12)$ üretici, \%34'ünün (n=15) kavramsallaştırıcı, $\% 20$ 'sinin ( $n=9)$ geliştirici ve \%18'inin ( $n=8)$ uygulayıc1; "görsel sanatlar yetenek alanı" öğrencilerinin \%24'ünün ( $n=10)$ üretici, \%45'inin ( $n=19)$ kavramsallaştırıcı, \%17'sinin ( $n=7)$ geliştirici ve \%14'ünün (n=6) uygulayıcı YPÇ stiline sahip oldukları görülmektedir. Bununla birlikte genel zihinsel yetenek alanındaki öğrencilerin YPÇ stillerinden en fazla geliştirici ve uygulayıcı stili (\%28) en az kavramsallaştırıcı stili (\%22) tercih ettikleri, müzik alanındaki öğrencilerin YPÇ stillerinden en fazla kavramsallaştırıcı stili (\%34) en az uygulayıcı stili (\%18), görsel sanatlar alanındaki öğrencilerin ise YPÇ stillerinden en fazla kavramsallaştırıcı stili (\%45) en az uygulayıcı stili (\%14) tercih ettiği söylenebilir.

\section{Sonuç, Tartışma ve Öneriler}

Bu çalışmada özel yetenekli öğrencilerin YPÇ stilleri ve YPÇ stillerinin farklı değişkenler ile ilişkisi incelenmiştir. Araştırmanın sonuçlarına göre özel yetenekli öğrencilerin YPÇ sürecinde en fazla kavramsallaştırıcı stili, en az uygulayıcı stili tercih ettiği belirlenmiştir. Kavramsallaştırıcı stil; soyut düşünerek bilgi elde etmeyi, yeni fikirlerin bir araya getirilmesini, problemlerin tanımlanması için teorik modeller oluşturma süreçlerini içermektedir (Basadur et al.,2014). Özel yetenekli öğrencilerin YPÇ sürecinde; problem durumunu net bir şekilde kavrayarak hareket etmeyi, problemleri kapsamlı bir şekilde tanımlamayı, tanımladıkları problemlerin çözümüne yönelik çok sayıda fikir üretmeyi ve problem çözüm sürecini sonlandırmaktan ziyade fikirlerle uğraşmayı tercih ettikleri söylenebilir. Bu bulgunun tersine üniversite öğrencileri ile gerçekleştirilen bir çalışmada (Peterson, 2006) öğrenciler en fazla uygulayıcı stili en az geliştirici stili tercih ederken diğer bir çalışmada 
(Basadur et al., 1990) en fazla geliştirici stili en az kavramsallaştırıcı stili tercih etmiştir. Bu duruma kültür, öğretim etkinliklerinin içeriği, toplam eğitim süresi ve lisans alanı gibi değişkenlerin etkili olduğu düşünülmektedir.

Cinsiyete göre yapılan değerlendirmede özel yetenekli öğrencilerin YPÇ stillerinin cinsiyetlerine göre farklılık göstermediği belirlenmiştir. Diğer bir ifade ile cinsiyet değişkeninin öğrencilerin problem çözme sürecindeki stil tercihlerini etkilemediği söylenebilir. Ancak kız öğrencilerin YPÇ stillerinden en fazla kavramsallaştırıcı stili en az geliştirici stili tercih ettikleri erkek öğrencilerin ise en fazla kavramsallaştırıcı stili en az uygulayıcı stili tercih ettikleri görülmüştür.

Yetenek alanlarına göre yapılan değerlendirmede ise, öğrencilerin YPÇ stilleri ile yetenek alanları arasında zayıf düzeyde ve anlamlı bir ilişkinin olduğu belirlenmiştir. Öğrencilerin YPÇ stilleri yetenek alanlarına göre anlamlı şekilde farklılık göstermiştir. Genel zihinsel yetenek alanı öğrencileri problem çözme sürecinde en fazla geliştirici ve uygulayıcı stili, en az üretici stili tercih etmiştir. Öğrencilerin YPÇ sürecinde; üretilen çözüm fikirlerini sistematik olarak analiz edip değerlendirmeyi, çözümün uygulanması için eylem planı hazırlamayı, çözümün uygulanmasında karşılaşılabilecek olumlu ve olumsuz durumları tahmin edip önlemler almayı ve çözümün etkililiğini değerlendirmeyi tercih ettikleri söylenebilir.

Müzik ve görsel sanatlar yetenek alanı öğrencileri problem çözme sürecinde en fazla kavramsallaştırıcı stili, en az ise uygulayıcı stili tercih etmiştir. Öğrencilerin YPÇ sürecinde; problem alanı ile ilgili çok fazla sayıda problem belirlemeyi, olası problemleri farklı açılardan incelemeyi, en önemli problemi belli başlı kriterlere göre seçmeyi, belirlenen problemi çözmek için fazla sayıda olası çözüm fikirleri üretmeyi tercih ettikleri söylenebilir.

Genel zihinsel yetenek alanı öğrencileri problem çözme sürecinde ayrıntılı plan yapmayı, geliştirilen planı uygulamayı ve değerlendirmeyi tercih ederken müzik ve görsel sanatlar yetenek alanı öğrencileri belirlenen probleme ilişkin çok sayıda fikir ve çözüm önerisi üretmeyi tercih etmiştir. Basadur vd. (2014) bireylerin yeteneklerinin ve mesleklerinin YPÇ stillerini etkilediğini ifade etmektedir. Üretici stilin baskın olduğu mesleklerin öğretmenlik ve akademisyenlik; kavramsallaştırıcı stilin baskın olduğu mesleklerin stratejik planlama, tasarım ve sanat; geliştirici stilin baskın olduğu mesleklerin mühendislik, finans ve bilişim sistemleri; uygulayıcı stilin baskın olduğu mesleklerin halkla ilişkiler, proje yürütücülüğü, satış uzmanı ve lojistik olduğunu belirtmiştir.

Wellman (2014) görsel iletişim teknolojileri alanında çalışmak isteyen öğrencilerin geliştirici stile, mimarlık ve çevre düzenlenmesi alanında çalışmak isteyen öğrencilerin kavramsallaştırıcı stile, yapı yönetimi alanında çalışmak isteyen öğrencilerin geliştirici stile, havacılık alanında çalışmak isteyen öğrencilerin uygulayıcı stile sahip olduklarını tespit etmiştir.

İlgili çalışmalar incelendiğinde bireylerin farklı stillere sahip oldukları, yeteneklerin ve mesleklerin stillerinin dağılımını etkilediği anlaşılmaktadır. Herhangi bir YPÇ stilinin diğerine üstünlüğü yoktur ve bütün stiller eşit derecede öneme sahiptir (Basadur \& Goldsby, 2016). Örgütlerde ve çalışma gruplarında stil bakımından heterojen bir yapının kurulması gerçekleştirilen çalışmanın daha kaliteli ve inovatif olmasına katkı sağlamaktadır (Basadur et al., 2014). Yaratıcılık ve problem çözme becerileri açısından ön plana çıkan özel yetenekli öğrencilerin YPÇ stillerinin belirlenmesi ve bu 
stillerin geliştirilmesi yönünde öğretimin sağlanmasının önemli olduğu düşünülmektedir. Öğrencilerin YPÇ stillerinin gelişimi açısından:

Üretici stil, problem bulma ve bilgi toplama etkinliklerini içermektedir. Öğrencilerin akademik çalışmalarda yargılanmadan veri toplamaları bu stilin gelişimi için gereklidir. Bu stilin gelişimine yönelik olarak; 5N1K, zihin haritaları, balık kılçı̆̆ı diyagramı, beyin fırtınası, özellik listeleme, teleskop, morfolojik analiz teknikleri kullanılabilir (Basadur \& Goldsby, 2016; Boulden, 2002; Cook 1998; Čančer 2012).

Kavramsallaştırıcı stile sahip birey uygun bir kapsamda problemi açık ve anlaşılır bir biçimde formüle eder. Öğrenciler tarafından araştırmaların problem durumlarının oluşturulması iyi bir görevdir. Kavramsallaştırıcı stil problemi tanımlama ve fikir bulma etkinliklerini içermektedir. Bu stilin gelişimine yönelik olarak; beyin fırtınası, özellik listeleme, kontrol listesi, ne-neden engel analizi, bağlantı kurma, prototip oluşturma, kriter tablosu teknikleri kullanılabilir (Basadur \& Goldsby, 2016; Boulden, 2002; Cook, 1998; Čančer 2012).

Geliştirici stile sahip birey soyut fikirleri ve alternatifleri pratik çözümlere ve planlara dönüştürür. Geliştirici stil değerlendirme ve seçme ile plan oluşturma etkinliklerini içermektedir. Bu stilin gelişimine yönelik olarak; çok kriterli karar verme, ikili karşılaştırma, nominal gruplama, kontrol listeleri, kritik yol analizi, varlık ilişki diyagramları, akış şemaları ile kavram haritaları teknikleri kullanılabilir (Basadur \& Goldsby, 2016; Boulden, 2002; Cook, 1998; Čančer, 2012).

Uygulayıcı stile sahip bireyler çözümü zihinde test etmek yerine hemen uygulamayı ve sonuç almayı ister. Uygulayıcı stil kabul oluşturma ve uygulama etkinliklerini içermektedir. Bu stilin gelişimine yönelik olarak; sonuç değerlendirme, etki analizi, eylem planı, risk analizi, varlık ilişki diyagramları, akış şemaları ile kavram haritaları teknikleri kullanılabilir (Basadur \& Goldsby, 2016; Boulden 2002; Cook, 1998; Čančer, 2012).

Bu çalışma, Türkiye'nin farklı bölgelerindeki BİLSEM'e kayıtlı öğrencilerin katılımı gerçekleştirilebilir. Öğrencilerin YPÇ stilleri sınıf düzeyleri, okul türleri, BİLSEM'e devam ettiği süre, ebeveyn eğitim durumları gibi değişkenlere göre de incelenebilir. Ayrıca tanılanmamış öğrencilerin YPÇ stilleri ile özel yetenekli öğrencilerin stillerini karşılaştıran çalışmaların ilgili literatüre katkısı açısından önemli olabileceği düşünülmektedir.

\section{Kaynakça}

Akdeniz, H. ve Bangir Alpan, G. (2019, Ekim). Özel yetenekli öğrencilerin yaratıcı problem çözme stillerinin analizi. VI. Ulusal Üstün Yeteneklilerin Eğitimi Kongresi'nde sunulmuş bildiri, İstanbul Üniversitesi, İstanbul.

Amabile, T. M. (1983). The social psychology of creativity: A componential conceptualization. Journal of Personality and Social Psychology, 43(2), 357-376.

Amabile, T. M., \& Gryskiewicz, N. D. (1989). The creative environment scales: Work environment inventory. Creativity Research Journal, 2(4), 231-253. doi: 10.1080/10400418909534321

Basadur, M., \& Goldsby, M. (2016). Design-centered entrepreneurship. New York: Routledge.

Basadur, M., \& Hausdorf, P. A. (1996). Measuring divergent thinking attitudes related to creative problem solving and innovation management. Creativity Research Journal, 9(1), 21-32. 
Basadur, M., Gelade, G., \& Basadur, T. (2014). Creative problem-solving process styles, cognitive work demands, and organizational adaptability. Journal of Applied Behavioral Science, 50(1), 80-115. doi: 10.1177/0021886313508433

Basadur, M., Gelade, G., Basadur, T., \& Perez, R. (2016). Improved reliability and research applications of the Basadur creative problem solving profile (CPSP). Kindai Management Review, 4, 100-112.

Basadur, M., Graen, G., \& Green, S. G. (1982). Training in creative problem solving: Effects on ideation and problem finding and solving in an industrial research organization. Organizational Behavior and Human Performance, 30(1), 41-70. doi: 10.1016/0030-5073(82)90233-1

Basadur, M., Graen, G., \& Wakabayashi, M. (1990). Identifying individual differences in creative problem solving style. The Journal of Creative Behavior, 24(2), 111-131.

Beghetto, R. A. (2010). The Cambridge handbook of creativity. New York, NY: Cambridge University.

Boulden, G. P. (2002). Thinking creatively. London: Dorling Kindersley.

Brophy, D. R. (1998). Understanding, measuring, and enhancing individual creative problem-solving efforts. Creativity Research Journal, 11, 123-150.

Brown, R. T. (1989). Creativity: What are we to measure? In J. A. Glover, R. R. Ronning, \& C. R. Reynolds (Eds.), Handbook of creativity (3-321). New York: Plenum Press.

Büyüköztürk, Ş., Çakmak, E. K., Akgün, Ö. E., Karadeniz, Ş. ve Demirel, F. (2014). Bilimsel araştırma yöntemleri. Ankara: Pegem Akademi.

Čančer, V. (2012). Criteria weighting by using the 5Ws \& H technique. Business Systems Research, $3(2), 41-48$.

Carr, M., \& Borkowski, J. G. (1987). Metamemory in gifted children. Gifted Child Quarterly, 31(1), 40-44. doi: 10.1177/001698628703100109

Chien, C., \& Hui, A. N. N. (2010). Creativity in early childhood education: Teacher's perception in three Chinese societies. Thinking Skills and Creativity, 5(2), 49-60.

Cohen, J. (1988). Statistical power for the social sciences. Hillsdale, NJ: Laurence Erlbaum and Associates.

Conklin, W., \& Frei, S. (2007). Differentiating the curriculum for gifted learners. Huntington Beach, CA: Shell Education.

Cook, P. (1998). Best practice creativity. Hampshire: Gower.

Couger, J. D. (1995). Creative problem solving and opportunity finding. Danvers: Boyd \& Fraser Pub Co.

Creswell, J. W. (2012). Planning, conducting, and evaluating quantitative and qualitative research. Boston, MA: Pearson.

Çetinkaya, Ç. (2013). The effect of gifted students' creative problem solving program on creative thinking. Procedia-Social and Behavioral Sciences, 116(2014), 3722-3726.

Çitil, M. ve Ataman, A. (2018). İlköğretim çağındaki üstün yetenekli öğrencilerin davranışsal özelliklerinin eğitim ortamlarına yansıması ve ortaya çıkabilecek sorunlar. Gazi Üniversitesi Gazi Ĕ̆itim Fakültesi Dergisi, 38(1), 185-231.

Demirci, N. (2014). Sistematik yaratıcı problem çözme etkinliklerinin ilköğretim 7. sınıf öğrencilerinin ışık konusundaki kuramsal, deneysel ve günlük yaşam problemlerini çözmelerine etkisi (Yayınlanmamiş doktora tezi). Marmara Üniversitesi Eğitim Bilimleri Enstitüsü, İstanbul, Türkiye.

Erkuş, A. (2016). Psikolojide ölçme ve ölçek geliştirme-I. Ankara: Pegem Akademi.

Fowler, F. J. (2009). Applied social research methods: Survey research methods. Thousand Oaks, CA: SAGE Publications.

Guilford, J. P. (1950). Creativity. American Psychologist, 5, 444-454.

Gurak-Ozdemir, S., Acar, S., Puccio, G., \& Wright, C. (2019): Why do teachers connect better with some students than others? Exploring the influence of teachers' creative-thinking preferences. Gifted and Talented International, 34(1-2), 102-115. 
Gürbüz, S. ve Şahin, F. (2017). Sosyal bilimlerde araştırma yöntemleri. Ankara: Seçkin.

Isaksen, S. G., \& Treffinger, D. J. (1985). Creative problem solving: The basic course. Buffalo, NY: Center for Studies in Creativity.

Isaksen, S. G., \& Treffinger, D. J. (2004). Celebrating 50 years of reflective practice: Versions of creative problem solving. Journal of Creative Behavior, 38(2), 75-101.

Isaksen, S. G., Dorval, K. B., \& Treffinger, D. J. (1994). Creative approaches to problem solving. Dubuque, IA: Kendall-Hunt.

Isaksen, S. G., Dorval, S. G., \& Treffinger, D. J. (2011). Creative approaches to problem solving: A framework for innovation and change (3rd ed.). Thousand Oaks, CA: Sage.

İslim, Ö. F. (2009). Bilgi ve iletişim teknolojileri dersinin scamper(yönlendirilmiş beyin fırtınası) tekniğgine göre işlenmesinin öğrencilerin yaratıcı problem çözme becerilerine ve akademik başarılarına etkisi (Yayınlanmamış yüksek lisans tezi). Gazi Üniversitesi Eğitim Bilimleri Enstitüsü, Ankara, Türkiye.

Karabey, B. (2010). Illköğretimdeki üstün yetenekli öğrencilerin yaratıcı problem çözmeye yönelik erişi düzeylerinin ve kritik düşünme becerilerinin belirlenmesi (Yayınlanmamış doktora tezi). Dokuz Eylül Üniversitesi Eğitim Bilimleri Enstitüsü, İzmir, Türkiye.

Karasar, N. (2019). Bilimsel araştırma yöntemi (34. bs.). Ankara: Nobel Yayıncılık.

Meadow, A., Parnes, S. J., \& Reese, H. W. (1959). Influence of brainstorming instructions and problem sequence on a creative problem-solving test. Journal of Applied Psychology, 43, 413-416. doi:10.1037/h0043917

MEB (2019). Bilim ve sanat merkezleri yönergesi. https://orgm.meb.gov.tr/www/mevzuat/icerik/608 adresinden erişilmiştir.

Mumford, M. D., Baughman, W. A., Threlfall, K. V., Supinski, E. P., \& Costanza, D. P. (1996). Process-based measures of creative problem-solving skills: I. problem construction. Creativity Research Journal, 9(1), 63-76.

O'Quin, K., \& Besemer, S. P. (1989). The development, reliability, and validity of the revised creative product semantic scale. Creativity Research Journal, 2(4), 267-278. doi: 10.1080/10400418909534323

Olgun, E. (2012). A non-formal learning program for the contribution of creative problem solving skills: A case study (Unpublished master's thesis). Bilkent University, Ankara, Turkey.

Osborn, A. F. (1953). Applied imagination: Principles and procedures of creative problem solving. New York: Charles Scribner's Sons.

Önol, M. (2013). Yaratıcı problem çözme etkinliklerinin bilimsel süreç becerilerine ve başarıya etkisi (Yayınlanmamış yüksek lisans tezi). Balıkesir Üniversitesi Fen Bilimleri Enstitüsü, Balıkesir, Türkiye.

Özkök, A. (2004). Disiplinlerarası yaklaşıma dayalı yaratıcı problem çözme öğretim programının yaratıcı problem çözme becerisine etkisi (Yayınlanmamış doktora tezi). Gazi Üniversitesi Ĕ̈itim Bilimleri Enstitüsü, Ankara, Türkiye.

Parnes, S. J. (1967). Creative behavior guidebook. New York: Charles Scribner's Sons.

Parnes, S. J., Noller, R. B., \& Biondi, A. M. (1977). Guide to creative action. New York: Charles Scribner's Sons.

Peterson, C. M. (2006). Creative problem solving styles and learning strategies of management students: implications for teaching, learning, and work (Unpublished doctoral dissertation). Oklahoma State University, Stillwater, Oklahoma.

Puccio, G. J. (2017). From the dawn of humanity to the 21st century: Creativity as an enduring survival skill. The Journal of Creative Behavior, 51, 330-334.

Runco, M. A., \& Nemiro, J. (1994). Problem finding and problem solving: Problem finding, creativity, and giftedness. Roeper Review, 16(4), 235-241. 
Runco, M. A., Dow, G., \& Smith, W. R. (2006). Information, experience, and divergent thinking: An empirical test. Creativity Research Journal, 18, 269-277.

Sak, U. (2009).Üstün yetenekliler eğitim programları. Ankara: Maya Yayıncılık.

Sak, U. (2012). Üstün zekâlılar özellikleri tanılanmaları eğitimleri (2. bs.). Ankara: Maya Yayıncılık.

Sak, U. (2016). Yaratıcılık gelişimi ve geliştirilmesi. Ankara: Vize Yayıncılık.

Saranlı, A. G. (2017). Okul öncesi dönemdeki erken müdahale uygulamalarına farklı bir bakış: Üstün yetenekli çocuklar için erken zenginleştirme. Eğitim ve Bilim, 42(190) 343-359.

Seelig, T. (2012). in Genius: A crash course on creativity. NY: Harpercollins.

Senemoğlu, N. (2012). Gelişim öğrenme ve öğretim (22.bs.). Ankara: Pegem.

Simon, H. A. (1960). The new science of management decision. Englewood Cliffs, NJ: Prentice-Hall.

Snyder, A., Mitchell, J., Bossomaier, T., \& Pallier, G. (2004). The Creativity quotient: An objective scoring of ideational fluency. Creativity Research Journal, 16(4), 415-420.

Sternberg, R. J. (2006). The nature of creativity. Creativity Research Journal, 18(1), 87-98.

Tardif, T. Z., \& Sternberg, R. J. (1988). What do we know about creativity? In R. J. Sternberg (Ed), The nature of creativity: contemporary psychological perspectives (pp.429-440). Cambridge: Cambridge University Press.

Tennant, M., McMullen, C., \& Kaczynski, D. (2009). Teaching, learning and research in higher education: A critical approach. New York: Routledge.

Titus, P., \& Koppitsch, S. (2018). Exploring business students' creative problem-solving preferences. Journal of Education for Business, 93(5), 242-251.

Torrance, E. P. (1974). The Torrance tests of creative thinking: Norms-technical manual. Princeton, NJ: Personal Press.

Torrance, P. (1962). Guiding creative talent. USA: Prentice-Hall.

Treffinger, D. J. (2001). The importance of creative learning and problem solving. DImagiNings (Destination ImagiNation newsletter), 2(2), 10-12.

Treffinger, D. J. (2003). Talent development and creativity. Creative Learning Today, 12(4), 1-2.

Treffinger, D. J., \& Isaksen, S. G. (2005). Creative problem solving: The history, development, and implications for gifted education and talent development. Gifted Child Quarterly, 49, 342353.

Treffinger, D. J., \& Parnes, S. J. (1979). Creative problem solving for gifted and talented students. Roeper Review, 2(4), 31-32.

Trilling, B., \& Fadel, C. (2009). 21st century skills: Learning for life in our times. San Francisco: JosseyBass.

VanGundy, A. B., Jr. (1988). Techniques of structured problem solving. New York: Van Nostrand Reinhold.

Wallach, M. A., \& Kogan N. (1965). Modes of thinking in young children: A study of the creativity intelligence distinction. New York: Holt, Rinehart \& Winston.

Ward, T. B., Smith, S. M., \& Finke, R. A. (1999). Creative cognition. In R. J. Sternberg (Ed.), Handbook of creativity (189-212). England: Cambridge University Press.

Wellman, J. (2014). Relationship between creative problem solving profiles and career choice. Honors projects, 93. Retrieved from https://scholarworks.bgsu.edu/honorsprojects/93

Yıldırım, A. (2014). Okul öncesinde yaratıcı problem çözme etkinliklerinin yaratıcılığa etkisi (5 yaş örneği) (Yayınlanmamış doktora tezi). Hacettepe Üniversitesi Eğitim Bilimleri Enstitüsü, Ankara, Türkiye.

Yılmaz, M. (2019). Program görselleştirme aracıyla gerçekleştirilen dijital öyküleme etkinliklerinin yaratıcı problem çözme becerisi ve bilgisayara yönelik tutum üzerindeki etkisi (Yayınlanmamış yüksek lisans tezi). Atatürk Üniversitesi Eğitim Bilimleri Enstitüsü, Erzurum, Türkiye. 